\title{
Incidence of Schistosoma Haematobium and Trichomonas Vaginalis among Occupational Status of Patients Attending Some Selected Hospitals in Gboko, Benue State of Nigeria
}

\author{
Gberikon, G.M.1 ; Aguoru, C.U1; Yandev, D1
}

${ }^{1}$ University of Agriculture Makurdi, Benue state

\begin{abstract}
Investigations were carried out to ascertain the incidence of urinary parasitic infections caused by T.vaginalis and S.haematobium among patients attending selected hospitals in Gboko Local Government area of Benue State, Nigeria. Four major hospitals namely Division hospital, Myom hospital, General hospital and Mkar hospital all in Gboko were assessed. A total number of 400 urine samples (100 from each hospital) were aseptically collected for microscopic preparations and analyses. Data were analysed and presented using both descriptive and inferential statistics. In Division Hospital Gboko, 22\% of the patients were infected with T.vaginalis while $9 \%$ were infected with S.haematobium. In Myom Hospital Gboko, 9\% were infected with T.vaginalis while $12 \%$ were infected with S.haematobium. Mkar Hospital Gboko recorded 4\% cases of infection with T.vaginalis while $6 \%$ were infected with S.haematobium with a case of co-infection. General Hospital Gboko recorded the highest number of infection cases with $26 \%$ T.vaginalis , $41 \%$ S.haematobium and 9\% co-infection . Based on occupational status from combined data, farmers recorded the highest prevalence of $8.5 \%$ (T.vaginalis) and 6.25\% (S.haematobium), followed by students and entrepreneurs Combined data from the four hospitals using a population size of 400 patients in Gboko Local Government, the total prevalence rate of infection caused by T.vaginalis was $15.25 \%$ and S.haematobium $17 \%$, coinfection was prevalent at $2.5 \%$. Statistically, there was no significant levels of associations between urinary tract infections and occupational status of patients with $95 \%$ confidence limit. This work has therefore revealed that farmers have high incidence rates of infections caused by T.vaginalis and S.haematobium due to their educational background and exposure. Hence, the need for an enlightenment program for this category of people attending different hospitals in Gboko Local Government area.
\end{abstract}

Keywords: T.vaginalis , S.haematobium, occupation, infection

\section{Introduction}

Schistosomiasis and Trichomoniasis are most common urinary tract parasitic diseases in humans, the former is caused by S.haematobium and the later by T.vaginalis (Jatau et al., 2006; Imarenezor et al., 2013). Schistosomiasis also called bilharziasis is a parasitic disease produced by the Platyhelminthes worm of the class trematode, genus Schistosoma. It is commonly known as blood fluke or flat worm which is common in developing countries. The disease is originally contacted by working, bathing, or swimming in water polluted by snails that carry the worms (Johnston and Mabey, 2008). Schistosomiasis is characterized by inflammation of the intestine, bladder, cancer, haematuria (blood in urine), and other organs. It is probably humanity's most serious parasitic infection, being endemic to some 74 countries and affecting at least 200 million people yearly in Africa (WHO, 2015). Trichomonas vaginalis, is the causative agent of trichomoniasis (Soper, 2004).This species is the most common pathogenic protozoan infections of humans (Johnston and Mabey, 2008). Transmission takes place usually directly because the trophozoite does not have a cyst (Uneke, 2006b).The World Health Organization (WHO) has estimated that 160 million cases of infections are acquired annually worldwide (Harp and Chowdhury, 2011). Infections rates between men and women are the same and usually with women showing symptoms, while infections in men are usually asymptomatic (Francalugo and Zarzosa, 2010).

\section{Materials and Methods}

Four major hospitals namely: General Hospital Gboko, Division Hospital Gboko, Myom Hospital Gboko and Mkar Hospital Gboko were assessed. A 
total of 400 urine samples were collected from patients across the four hospitals for analysis. 100 samples were collected from each of the hospitals which comprised 50 samples from male and 50 samples from female patients. The sample size was estimated using sample size calculator by Raosoft (2004).

\section{Collection of Urine Sample and Demographic Information}

Clean labeled aseptic bottles were given to the patients with instruction to produce mid-stream urine samples (Uneke, 2006b).Demographic biodata such as occupational status were obtained from the patients before sample collection and analysis. The urine samples were recorded and numbered for proper identification.

\section{Sample Analyses}

A sample set, consisting of 100 samples, was analysed one at a time from each hospital. All samples were analysed at Lens Gabriel School of Medical Laboratory Sciences Mkar, Benue State. Each urine sample was examined macroscopically for turbidity, presence of blood or cloudiness. For microscopic investigation, $2 \mathrm{ml}$ of each sample was poured in a centrifuge tube. The tubes (12 at a time) were balanced in the centrifuge machine to avoid splashing during spinning and were spun at 1500 revolution per minute for 5 minutes. From each tube, the supernatant was discarded. A drop of the deposit was transferred to a clean slide using Pasteur pipette and covered with a cover slip and viewed under the Light Binocular microscope at $\mathrm{x} 10$ and $\mathrm{x} 40$ objective lenses for the presence of ova of Schistosoma heamatobium and trophozoites of Trichomonas vaginalis. Result of each sample was recorded against the name and occupation of each patient.

\section{Data Analyses}

Data were pictorially represented through appropriate graphical analysis constructed from Microsoft Excel Sheet of 2010 version. Inferential Non-parametric Statistics was conducted on the combined data through the use of Chi-square test of hypothesis $\left(\chi^{2}\right)$. This was done to determine if there were associations between infections and occupational status of patients in the four selected hospitals. Chi- Square was manually computed through factorial analysis and the resulting calculated and tabulated values were used in decision rule (NMC, 2013).

\section{Results and Discussion}

\section{T.vaginalis S.haematobium}

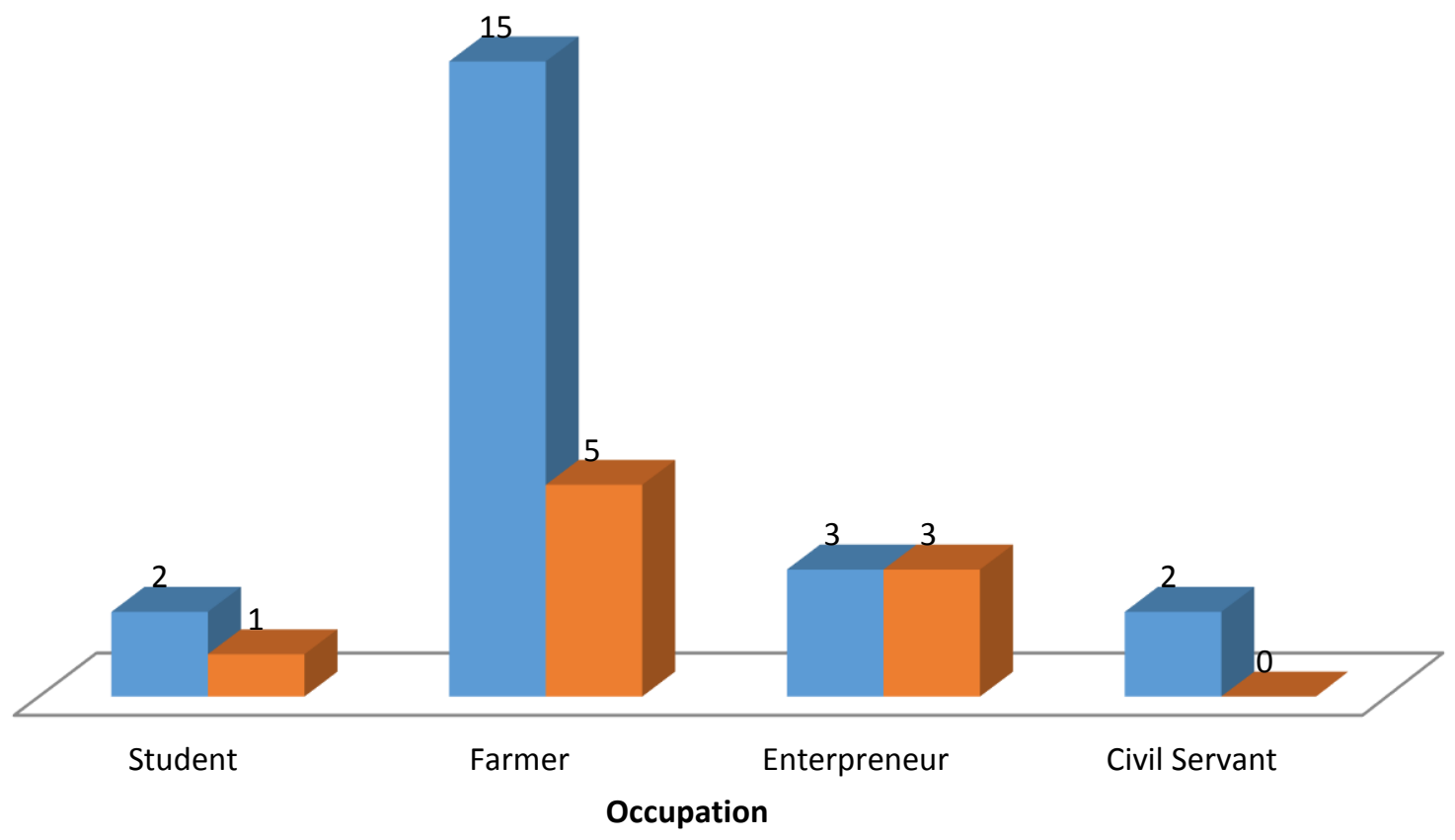

Figure 1: Distribution of occupation amongst infected patients in Division Hospital Gboko (N=100) 


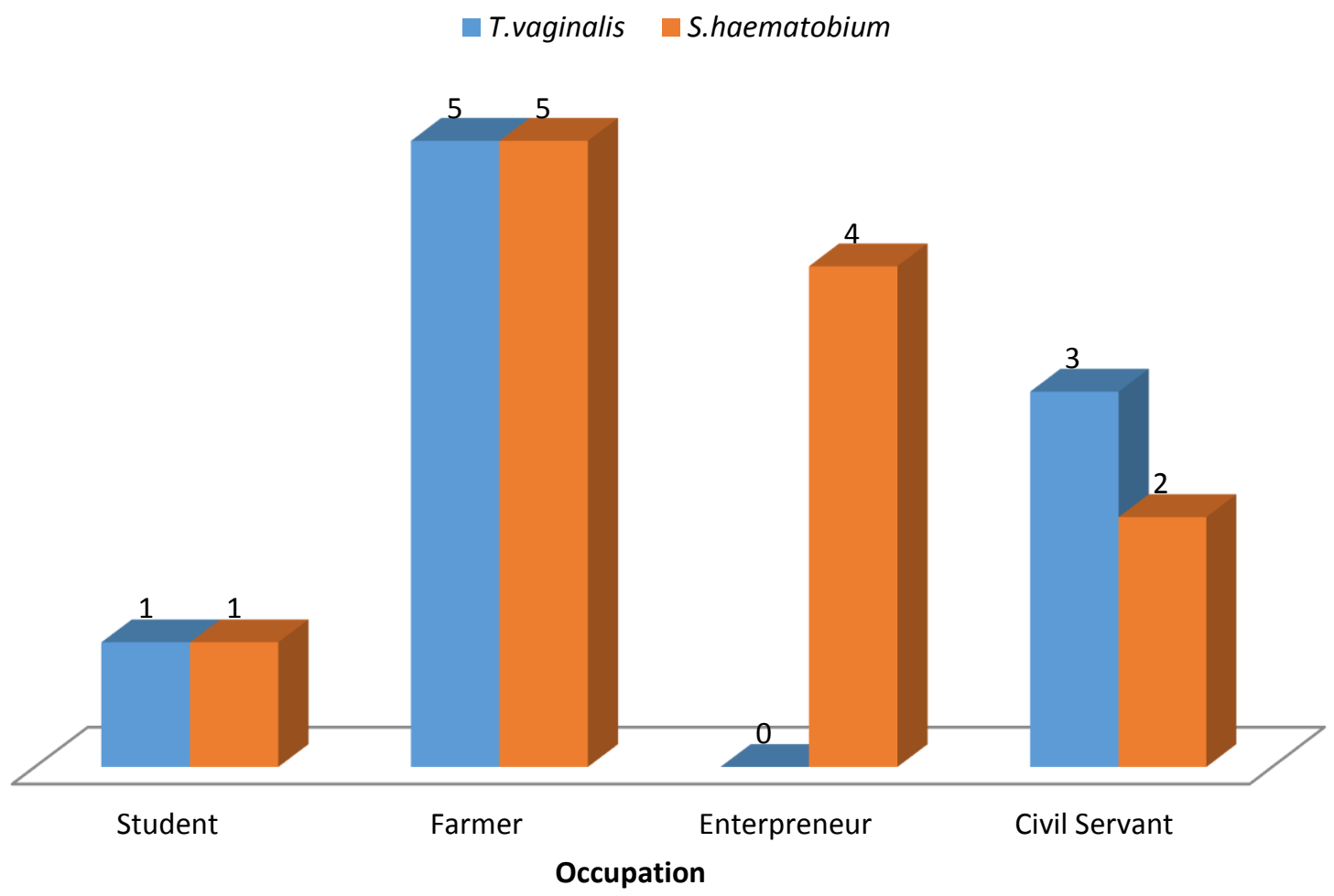

Figure 2: Occupation status of positive patients in Myom hospital, Gboko (N=100)

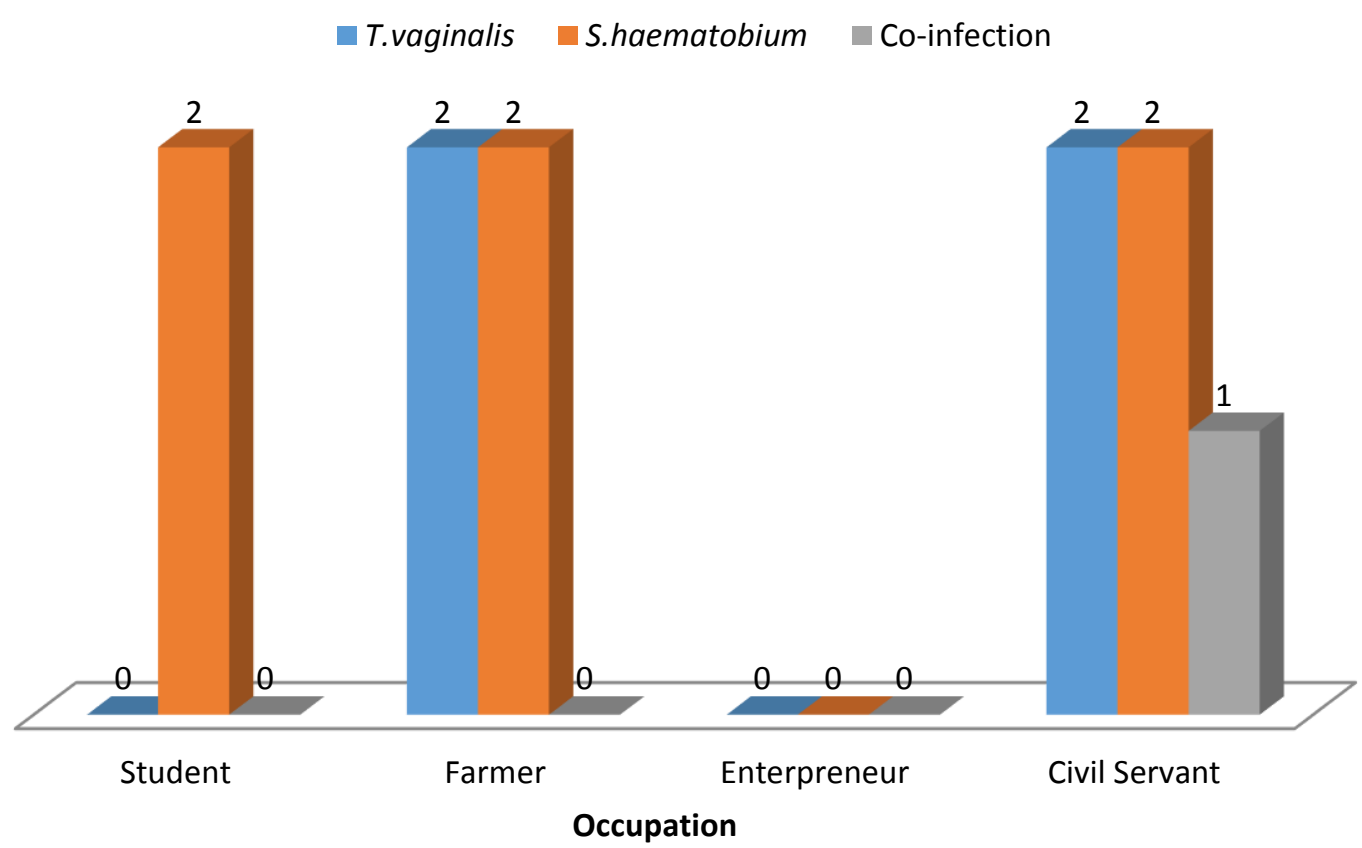

Figure 3: Distribution of infected patients based on occupation status in Mkar Hospital Gboko ( $N=100)$ 


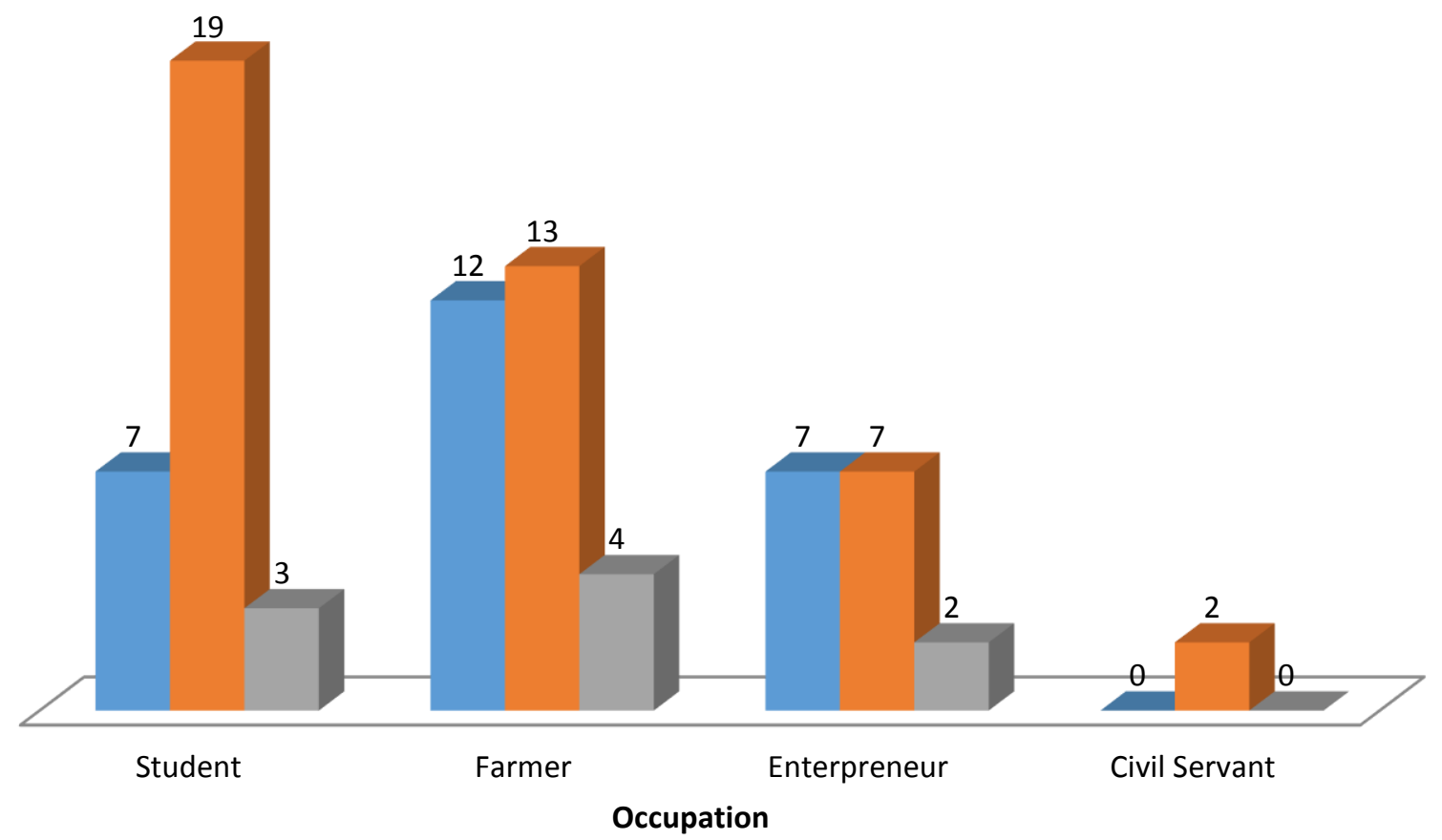

Figure 4: Distribution of infection cases in General Hospital Gboko based on occupation status $(\mathrm{N}=100)$

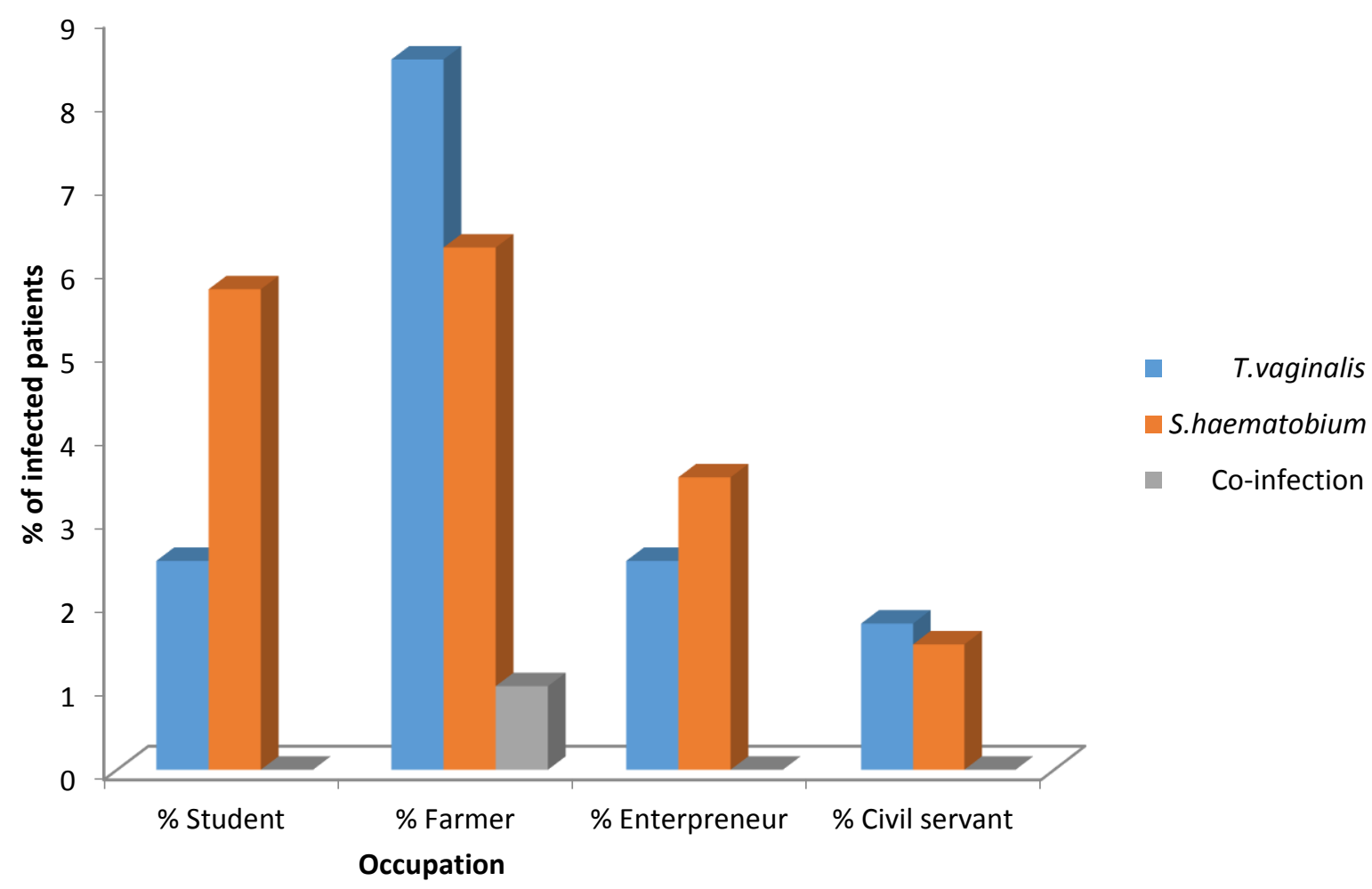

Figure 5: Occupation status of infected patients in Gboko L. G. Area (N=400) 


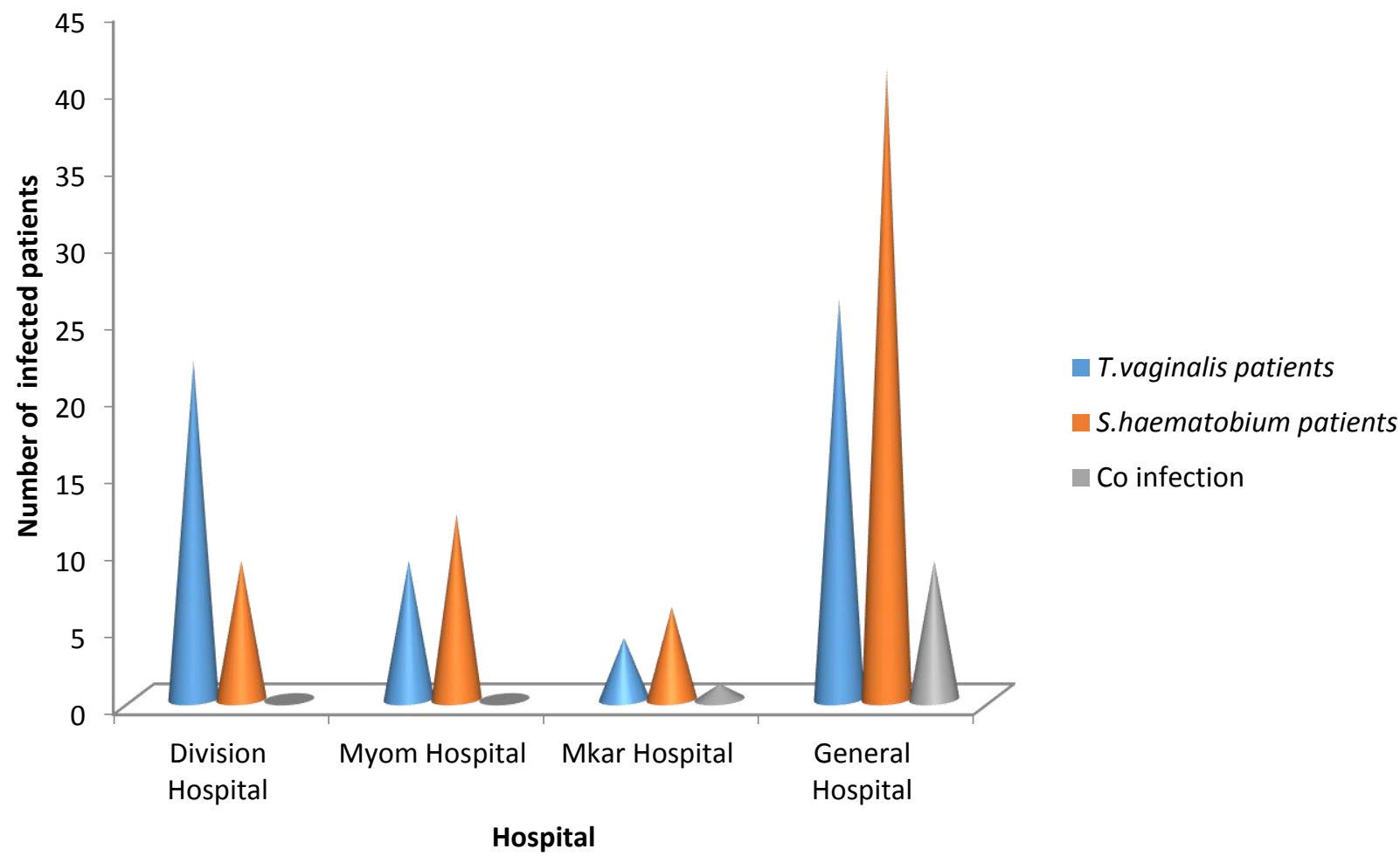

Figure 6: Prevalence of infections among the four hospitals based on occupation

\section{DISCUSSION}

Urinary tract infections are major parasitic infections affecting many people with different occupational background in Nigeria and other developing countries. The highest prevalence rate of T.vaginalis infection was recorded among patients in the General Hospital (26\%) followed by those in Division Hospital (22\%). It is worrisome to have also discovered that the General Hospital had the highest prevalence of $41 \%$ of S. haematobium cases among its patients with $9 \%$ of all examined patients co-infected with T.vaginalis and S.haematobium. This alarming rate at the General hospital may be attributed to the fact that services and health delivery are offered at affordable rates.

Based on the view of some authors (Adeyeba and Ojeaga, 2002; Uneke et al., 2006a; Chalechale and Karimi, 2010) it is statistically pertinent to interpret results from a larger sample size to communicate a more reliable findings. Hence, the combined result of all hospitals with a sample size of 400 patients is an eye opener to the high prevalence of the studied infections in Gboko Local Government Area of Benue State. The total prevalence rates of T.vaginalis $(15.25 \%)$, S.haematobium $(17 \%)$ and co-infection $(2.5 \%)$ were quite high in farmers who are ignorant of the existence of these two infections. This report has also revealed that farmers are more vulnerable to the two infections than other occupational status while civil servants are the least vulnerable. This could be attributed to level of illiteracy and low level of sex education among the farmers, hence their vulnerability, whereas civil servants, students and entrepreneurs are more informed. Farmers are often predisposed to water sources where the infectious stages of S.haematobium are contracted followed by students. According to Uneke (2006b), the development of irrigation schemes and contacts with flooded areas have increased the prevalence of S.haematobium infections in several continents. Hence, schistosomiasis is more prevalent in rural communities where the standard of hygiene is low due to poverty or lack of infrastructure to support adequate health care services (Adeyeba and Ojeaga,2002)

The view of Haytham et al. (2005), that urinary tract infections have cosmopolitan distribution identified in all racial groups and social economic status, is fully supported in this work. Meanwhile, these parasitic infections have been reported to have potential influence on the spread of HIV and other sexually transmitted infections (Johnston and Mabey, 2008). Therefore, between infection and occupational status, $\chi^{2}$ Calculated (7.0501) was less than $\chi^{2}$ Tabulated (12.592), therefore no association was established between the two variables. 


\section{CONCLUSION}

Based on the findings of this work, it has been concluded that trichomoniasis and schistosomiasis are more common among patients whose occupational status is mainly farming as opposed to other occupational status like civil servants and entrepreneurs. No statistically significant level of association was found between urinary infections and occupational status of patients used in this study attending selected hospitals in Benue state. Therefore, these parasites could be contracted irrespective of occupational profile of members in Gboko local government area.

\section{REFERENCES}

1) Adeyeba, O.A and Ojeaga, S.G. (2002). Urinary schistosomiasis and concomitant urinary tract pathogens among school children in metropolitan Ibadan, Nigeria. African Journal of Biomedical Research, 5: 103-107. http://dx.doi.org/10.4314/ajbr.v5i3.53993

2) Chalechale, A and Karimi, I. (2010). The Prevalence of Trichomonas vaginalis infection among patients presented to hospitals in the Kermanshah district of Iran in 2006 and 2007. Turkish Journal of Medical Sciences, 40(6):971-973

3) Francolugo, V. and Zarzosa, A. (2010). Urinary tract infection from Schistosoma haematobium: a case in Cuernavaca, Morelis, Mexico. Review of Mexican Urology, 70(3):187-192.

4) Harp, D.F. and Chowdhury, I.(2011). Trichomoniasis: Evaluation to Execution. European Journal of Obstetrics and Gynecology and Reproductive Biology, 157 (1): 3-9. http://dx.doi.org/10.1016/j.ejogrb.2011.02.024

5) Haytham, M.A., Nawfal,Y.A. and Ghada, A.A. (2005). The prevalence of Trichomonas vaginalis
6) in association with other microorganism among women with vaginal discharge in Mosul.

7) Annals of the College of Medicine Mosul, 31(1): 37-44.

8) Imarenezor, E.P.K., Nmorsi, O.P.G., Eghafona, N.O., Ohenhen, R.E. and Ekozien, M.I. (2013) http://dx.doi.org/10.14419/ijbas.v2i2.647

9) Prevalenve of Urinary Schistosomiasis in Nwana rural community in Akoko Edo Local http://dx.doi.org/10.14419/ijbas.v2i2.647

10) Government Area, Edo State. Nigeria. International Journal of Basic and Applied Sciences, 2(2): 189-192 http://dx.doi.org/10.14419/ijbas.v2i2.647

11) Jatau, E.D., Olanitola, O.S. and Olayinka, A.T. (2006) Prevalence of Trichomonas infection among women attending antenatal clinics in Zaria, Nigeria. Annals of African medicine, 5(4): 178-181.

12) Johnston, V.J. and Mabey, D.C. (2008). Global Epidemiology and Control of Trichomonas vaginalis. Current Opinion in Infectious Diseases, 21: 56-64 http://dx.doi.org/10.1097/qco.0b013e3282f3d999

13) National Mathematical Centre, Kwali, Abuja (2013) Descripitive and Inferential Statistical Data Analysis.International Workshop on Quality Data Management.

14) Soper, D. (2004). Trichomoniasis: Under Control or Under controlled? American Journal of Obstetrics and Gynecology, 190(1): 281-290. http://dx.doi.org/10.1016/j.ajog.2003.08.023

15) Uneke, C., Oyibo, P., Ugwuoru.,C.U., Nwanokwai, A., Iloegbunam, R. (2006a). Urinary schistosomiasis among school age children in Ebonyi State, Nigeria. The Internet Journal of Laboratory Medicine, 2(1): 11pp.

16) Uneke, C., Ugwuja, E., Isiogu, N., Iloegbunam, R; Elom, M. (2006b). An assessment of urine analysis, Trichomonas vaginalis and Schistosoma haematobium infections in women attending out-patients clinics in Southeastern Nigeria. The Internet Journal of Laboratory Medicine, 2(1). 11pp. http://dx.doi.org/10.5580/12b1

17) World Health Organisation, Geneva.(2015). Schistosomiasis Fact Sheet. Retrieved from www.who.org/infections 